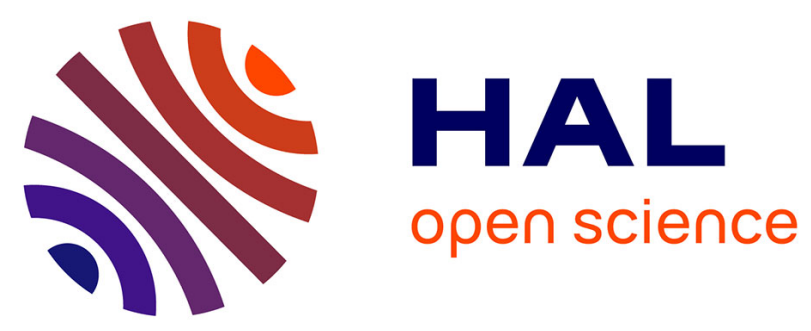

\title{
Low cost high specific surface architectured nanoporous metal with corrosion resistance produced by liquid metal dealloying from commercial nickel superalloy
}

Morgane Mokhtari, Takeshi Wada, Christophe Le Bourlot, Nicolas Mary, Jannick Duchet-Rumeau, Hidemi Kato, Éric Maire

\section{To cite this version:}

Morgane Mokhtari, Takeshi Wada, Christophe Le Bourlot, Nicolas Mary, Jannick Duchet-Rumeau, et al.. Low cost high specific surface architectured nanoporous metal with corrosion resistance produced by liquid metal dealloying from commercial nickel superalloy. Scripta Materialia, 2019, 163, pp.5-8. 10.1016/j.scriptamat.2018.12.023 . hal-02006918

\section{HAL Id: hal-02006918 https://hal.science/hal-02006918}

Submitted on 3 Jan 2022

HAL is a multi-disciplinary open access archive for the deposit and dissemination of scientific research documents, whether they are published or not. The documents may come from teaching and research institutions in France or abroad, or from public or private research centers.
L'archive ouverte pluridisciplinaire HAL, est destinée au dépôt et à la diffusion de documents scientifiques de niveau recherche, publiés ou non, émanant des établissements d'enseignement et de recherche français ou étrangers, des laboratoires publics ou privés. 


\title{
Low cost high specific surface architectured nanoporous metal with corrosion resistance produced by liquid metal dealloying from commercial nickel superalloy
}

\author{
Morgane Mokhtari a,b,c , Takeshi Wada a ${ }^{\mathrm{a}}$, Christophe Le Bourlot ${ }^{\mathrm{b}}$, Nicolas Mary ${ }^{\mathrm{b}, \mathrm{d}}$, Jannick Duchet-Rumeau ${ }^{\mathrm{c}}$, \\ Hidemi Kato $^{\mathrm{a}, *}$, Eric Maire ${ }^{\mathrm{b}}$ \\ a Institute for Materials Research, Tohoku University, Sendai 980-8577, Japan \\ b Univ Lyon, INSA Lyon, MATEIS, CNRS UMR5510, F-69621 Villeurbanne, France \\ ${ }^{c}$ Univ Lyon, INSA Lyon, IMP, CNRS UMR5223, F-69621 Villeurbanne, France \\ d ELyTMaX UMI3757, Tohoku University, Sendai 980-8577, Japan
}

\section{A R T I C L E I N F O}

\section{Article history:}

Received 13 November 2018

Accepted 15 December 2018

Available online 2 January 2019

\section{Keywords:}

Dealloying

Nickel superalloy

Porous material

Corrosion

Iron alloys

\begin{abstract}
A B S T R A C T
Liquids metal dealloying is a new technology to create porous materials. In this study, a commercial Incoloy 825 nickel superalloy is dealloyed for $1 \mathrm{~h}$ at 3 different temperatures to elaborate a fully porous FeCr-based metal with 3 different porous microstructures. The resulting porous metals showed unimodal pore distribution, hierarchical structure or, contain large ligaments inclusions. The passivation ability of the porous material was conformed irrespective of the microstructure. This letter proves the possibility of fabricating low cost high specific surface materials for electrochemical applications.
\end{abstract}

Stainless steels are widely used as structural and functional materials in their bulk form. Porous stainless steels with a high specific surface and corrosion resistance properties would be highly desired in catalyst environment [1]. Previously Wada et al. elaborated porous stainless steel material by liquid metal dealloying (named LMD) from $\mathrm{a}(\mathrm{FeCr})_{\mathrm{x}}-\mathrm{Ni}_{1-\mathrm{x}}$ precursor manufactured in their lab [2]. In an industrial context, LMD would require cheap and abundant precursors. The use of a commercial alloy as precursor is then an attractive solution. Recently commercial alloys (TA6V, 316L, CoCrMo alloy) were successfully dealloyed resulting in a porous layer at the surface [3-5]. To fully dealloy a bulk precursor, the sacrificial element concentration in the precursor has to be over the parting limit, which is around $20 / 25$ at.\% for $\mathrm{Ni}$ in $(\mathrm{Fe}-\mathrm{Cr}) / \mathrm{Ni}$ precursor [6]. If not, only the surface is impacted by the process. A strategy has been previously used in [7] to be above the parting limit: it was to pre-enrich a commercial alloy with the element which will be dealloyed. In this letter, instead of choosing a commercial steel alloy containing only a small amount of nickel, we selected a nickel based superalloy: the commercial Incoloy 825 (UNS N08825) [8]. This is a fcc single-phase solid solution with a typical composition of $\mathrm{Ni}$ $\sim 41-48$ at.\%, $\mathrm{Fe}>25$ at.\%, $\mathrm{Cr} \sim 23-28$ at.\%, Mo 1.6-2.6 at.\%, $\mathrm{Cu}$ $\sim 1.5-3$ at.\% and a small amount ( $<1$ at.\%) of Ti, C, Mn S, Si, Al. This material shows exceptional resistance to many aggressive corrosion environments [8]. Considering the mixing enthalpies of the constituents of this alloy with magnesium $\Delta H_{\text {mix }}$ [9] listed in Table $1, \mathrm{Ni}, \mathrm{Cu}$ and $\mathrm{Si}$ are expected to dissolve in $\mathrm{Mg}$, because of negative $\Delta H_{\text {mix }}$, while $\mathrm{Fe}, \mathrm{Cr}$, Mo and Ti should remain [10]. Since the Ni content exceeds the parting limit, the liquid metal dealloying reaction should occur throughout the whole bulk of the precursor, resulting in the formation of a porous monolith of $\mathrm{Fe}-\mathrm{Cr}$ based alloy with a high corrosion resistance capability. In this letter, we intend (i) to elaborate a fully porous $\mathrm{FeCr}$ with sub- $\mu \mathrm{m}$ pores and ligaments by dealloying a commercial nickel based superalloy, Incoloy 825, (ii) to get the smallest possible ligaments to have a high specific surface and (iii) to characterize the corrosion resistance of this new material.

The Incoloy 825 precursor was provided by Nilaco, Japan. Its elemental chemical composition was investigated with a scanning electron microscope (SEM; Carl Zeiss ULTRA 55, Oberkochen, Germany) equipped with an energy-dispersive X-ray spectrometer (EDX; Bruker AXS, Xflash, Billereca, MA, USA). The sample had the following atomic composition: $\mathrm{Ni}_{42} \mathrm{Fe}_{26} \mathrm{Cr}_{25} \mathrm{Cu}_{2} \mathrm{Mo}_{2} \mathrm{Ti}_{0.8} \mathrm{Si}_{0.6}$. Pure $\mathrm{Mg}$ was used as dealloying molten bath. The initial thickness of the Incoloy 825 precursor was reduced from $1.57 \mathrm{~mm}$ to $1 \mathrm{~mm}$ by cold-rolling. We directly cut coldrolled samples into $30 \times 20 \mathrm{~mm}^{2}$ rectangles, and used those as a precursor for LMD without any additional heat treatment. The precursor samples were immersed in a liquid Mg bath. Two series of sample were 
Table 1

Mixing enthalpy of elements $\mathrm{M}$ in Incoloy 825 with $\mathrm{Mg}$ [9], $\Delta H_{m i x, M g-M}$.

\begin{tabular}{llllllll}
\hline Element M & $\mathrm{Fe}$ & $\mathrm{Cr}$ & $\mathrm{Ni}$ & $\mathrm{Cu}$ & $\mathrm{Mo}$ & $\mathrm{Si}$ & $\mathrm{Ti}$ \\
\hline$\Delta H_{\text {mix }, M g-M}(\mathrm{~kJ} / \mathrm{mol})$ & +18 & +24 & -4 & -3 & +36 & -26 & +16 \\
\hline
\end{tabular}

immersed one for $3 \mathrm{~min}$ and one for $1 \mathrm{~h}$ at $983 \mathrm{~K}, 1033 \mathrm{~K}, 1093 \mathrm{~K}$ and $1153 \mathrm{~K}$. The dealloying process created a bicontinous microstructure with a stainless steel matrix and a Mg-rich phase network. The dealloying thickness was controlled by the time of immersion [11]. The dealloying for $3 \mathrm{~min}$ led to a partially dealloyed sample where the precursor remaining at the center and a dealloyed region is located at the edge of the sample. The dealloying for $1 \mathrm{~h}$ led to a fully dealloyed sample. The porous stainless steel was then obtained by selective dissolution of the $\mathrm{Mg}$ phase in a $3 \mathrm{M} \mathrm{HNO}_{3}$ solution for $15 \mathrm{~h}$ (aerated solution at room temperature).

The crystal structures were determined by X-ray diffraction (XRD; Rigaku Ultima IV, Tokyo, Japan) with $\mathrm{Cu} \mathrm{K} \alpha$ radiation. Samples crosssections were prepared using an Ar ion-beam polisher (EM-3500 Hitachi, Japan) and observed by SEM. The porous structures were characterized by using Fiji image-analysis software [12]. Electrochemical characterizations were conducted in a stagnant and aerated $0.1 \mathrm{M}$ $\mathrm{NaCl}$ aqueous solution ( $\mathrm{pH}$ 6.5) with a potentiostat (VP300, Biologic France). After an Open Circuit Potential (OCP) of $2 \mathrm{~h}$, the polarization curves were recorded in the voltage range of -200 to $200 \mathrm{mV} v \mathrm{~s}$ a $\mathrm{Ag}$ / $\mathrm{AgCl}$ reference electrode. A pure platinum electrode was used as the counter electrode.

Fig. 1(a) shows the SEM images and EDX elemental maps of the precursor's surfaces. Neither metallurgical defects nor atomic segregations were observed probably due to the cold-rolling step which highly affects the microstructure [13]. The XRD pattern in Fig. 1(b) confirms the fcc single phase structure of the Incoloy 825 and the absence of a secondary phase. A coupon of Incoloy 825 was dealloyed during $3 \mathrm{~min}$ to observe the precursor sample after recrystallization and during $1 \mathrm{~h}$ to observe the porous structure morphology. Fig. 2(a) presents SEM micrograph and EDX map of precursor sample part after 3 min Mg immersion at $1093 \mathrm{~K}$; Ti-rich precipitates are not present at this high temperature [14,15]. Fig. 2(b) displays a SEM micrograph after immersing in $\mathrm{Mg}$ for $1 \mathrm{~h}$ at $1093 \mathrm{~K}$ showing a bicontinous microstructure of sample cross-section. This microstructure is the one typically obtained after liquid metal dealloying. This microstructure is composed by a first phase enriched in $\mathrm{Cr}$ and $\mathrm{Fe}$ (Fig. 2(d)) and a second phase rich in Mg (Fig. 2(b)). Fig. 2(e) shows the sample surface of the bicontinous structure after chemical etching. The same image with higher magnification is shown in Fig. 2(f). The sample presents a typical surface obtained by LMD and etching with ligaments with homogeneous size. The composition presented in the inset highlights the absence of $\mathrm{Ni}$ and $\mathrm{Cu}$. The $\mathrm{Cr}$-Fe matrix is a sigma phase (Fig. 2(c)). The $\sigma$ phase has a tetragonal structure usually stabilized at high temperature and for high content of $\mathrm{Cr}$. Here, the addition of Mo and Si help the $\sigma$ phase stabilization [16-18]. The ligament size was estimated at $0.7 \mu \mathrm{m}$ ( $c f$. Table 2) which is much smaller than the value obtained with different composition of $\mathrm{Fe}-\mathrm{Cr}-\mathrm{Ni}$ homemade precursors [13]. We thus proved here the possibility to obtain a full porous sample with LMD using a commercial precursor. In the next part we attempted to reduce the size of the ligaments by performing liquid metal dealloying at lower temperature [19]. To understand the microstructure the ratio between minor element and $\mathrm{FeCr}$ amount was investigated.

Irrespective of the time of immersion in the Mg bath, no dealloying was initiated at temperatures below $950 \mathrm{~K}$. A similar trend was observed by Kim et al. on Nb-Ni precursor. This is attributed in [11] to the fact that the temperature needs to be high enough to activate the process. Fig. 3(a) presents the SEM micrographs and EDX maps of remaining precursor part of partially dealloyed sample after 3 min of immersion in $\mathrm{Mg}$ at $1033 \mathrm{~K}$. The remaining precursor sample presents an almost homogeneous composition except for some micrometer size Ti-rich inclusions (darker regions in the SEM micrograph). These Tirich inclusions were already mentioned in the literature [14,15]. Fig. 3 (b) displays a SEM micrograph after $1 \mathrm{~h}$ of immersion in $\mathrm{Mg}$ at $1033 \mathrm{~K}$ and chemical etching. The surface presents mainly small ligaments. However some inclusions with polygonal shapes display larger ligaments. The composition of this polygonal shape (Fig. 3(c) marked as 3 ) reveals that their composition corresponds to the composition of Ti-rich inclusions in the precursor (marked as 1) after dealloying while the composition of small ligaments matrix (marked as 4) corresponds to the composition after dealloying of precursor matrix (marked as 2). It can then be concluded that Ti-rich inclusions induce regions with large ligaments after LMD. The local composition of the sample is indeed likely to influence the dealloying and coarsening behavior leading to different ligament size.

A coupon of Incoloy 825 was also dealloyed during 3 min to observe the first instants of the process. For both soaking times, cross-sections before etching were observed and are shown in Fig. 3(d) (3 min at $1153 \mathrm{~K}$ (left)) and ( $1 \mathrm{~h}$ at $1153 \mathrm{~K}$ (right)). The arrow corresponds to the dealloying direction. For 3 min dealloying, no remarkable evolution in the microstructure depending on the position is observed. After $1 \mathrm{~h}$, the sample shows two regions. A $\sim 30 \mu \mathrm{m}$ thick layer can be observed at the surface with a fine dealloyed microstructure while deeper, a classical coarsened dealloyed microstructure is observed. This latter microstructure is the one expected after $1 \mathrm{~h}$ coarsening of the previous $3 \mathrm{~min}$ dealloyed sample. Fig. 3(e) presents the resulting surface after Mg immersion for $1 \mathrm{~h}$ at $1153 \mathrm{~K}$ and etching. A hierarchical structure is observed. Fig. 3(f) shows the EDX composition after Mg immersion. For 3 min dealloying (marked as 1 and 2) the composition is constant along the all depth of the sample. For $1 \mathrm{~h}$ dealloying the composition of the area located deeper than $30 \mu \mathrm{m}$ from the surface is the same as for the sample dealloyed for 3 min (marked as 4 ). The ligaments near the surface (marked as 3) however, are Mo-rich. This layer is created by different dissolution kinetics in $\mathrm{Mg}$ : the dealloying will remove element with fast dissolution kinetics and would lead to ligaments containing $\mathrm{Ti}, \mathrm{Si}, \mathrm{Mo}, \mathrm{Fe}$ and $\mathrm{Cr}$ but if one waits longer and at high temperature, the element with slow dissolution kinetics will also have time to dissolve into $\mathrm{Mg}$. Therefore, Fe and $\mathrm{Cr}$ would consequently be dissolved from the initial ligaments creating this hierarchical microstructure

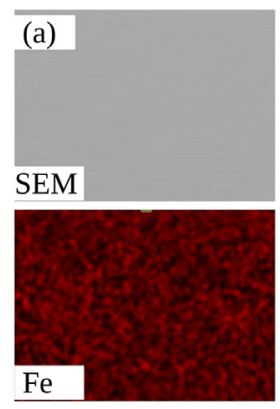

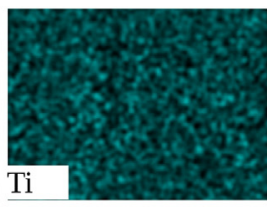
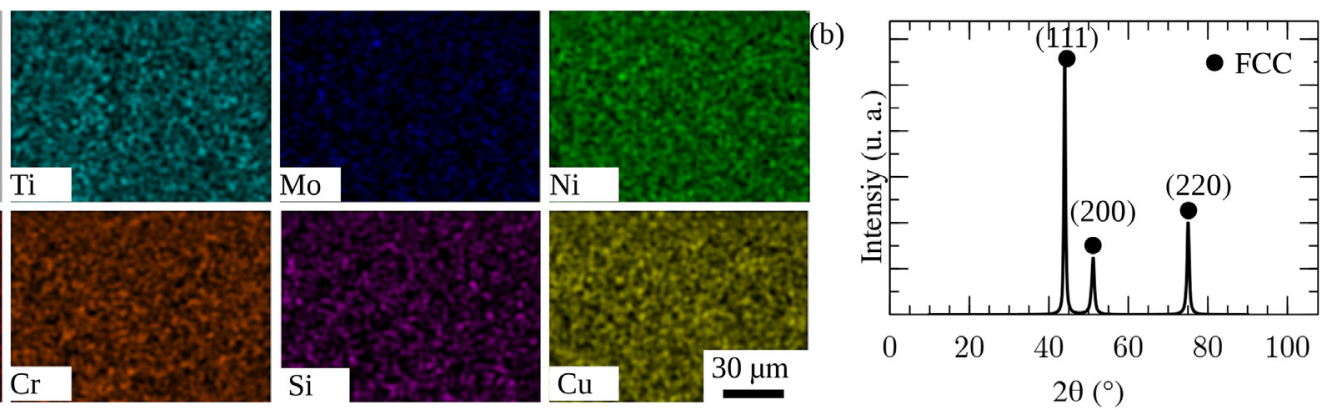

Fig. 1. (a) SEM micrograph and EDX map of precursor sample, and (b) XRD pattern of precursor sample. 

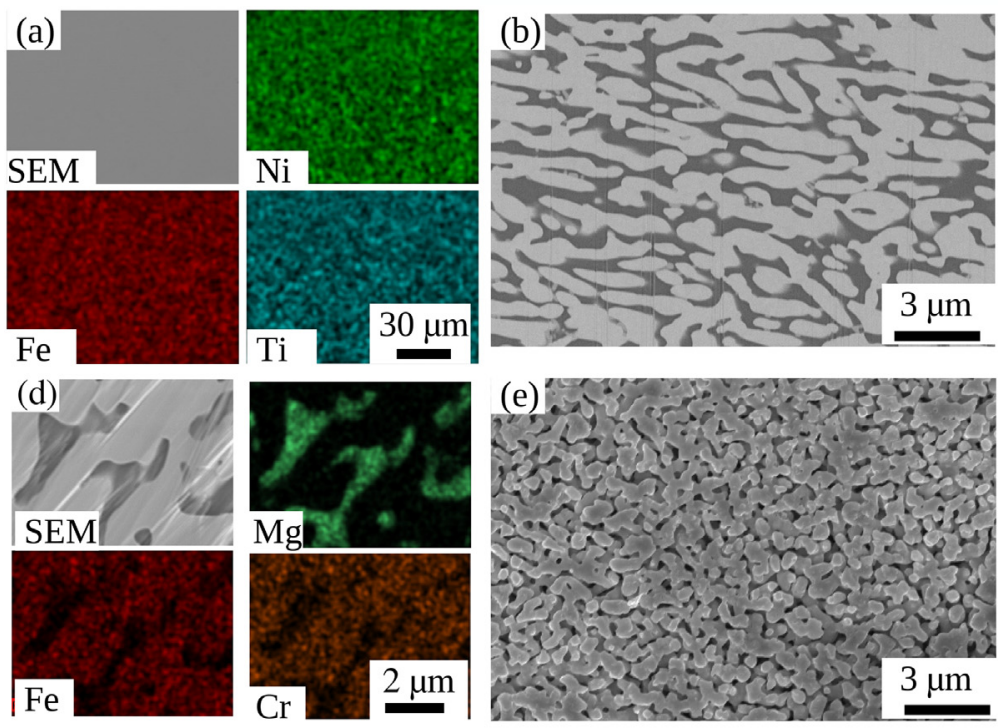

(c)

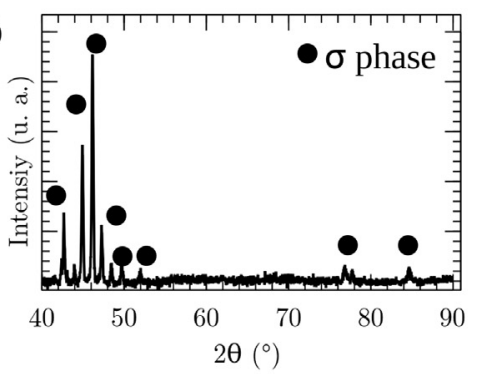

(f)

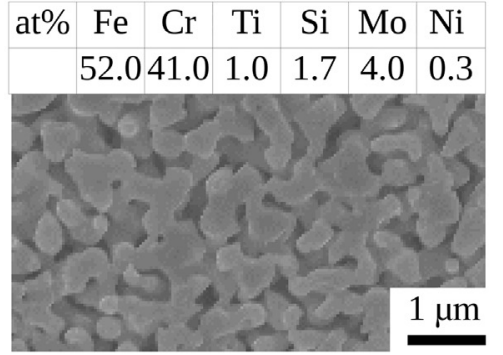

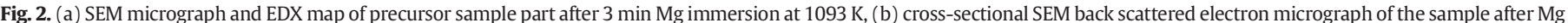

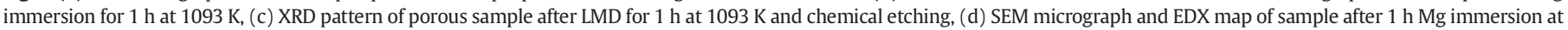

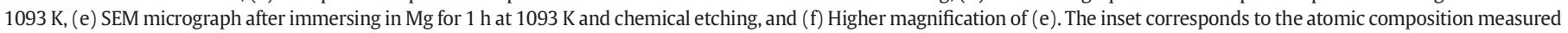
by SEM-EDX.

at the surface. Mo due to its higher melting temperature should remain inside ligaments. The dissolution of $\mathrm{Fe}$ and $\mathrm{Cr}$ inside $\mathrm{Mg}$ bath at high temperature was already mentioned in [3]. From polished cross-section SEM micrography of samples before etching (not necessary shown here), the porosity was measured to be $33 \pm 5 \%$. Ligaments size were measured on the porous structure and are reported in Table 2. While comparing regions with the same composition after dealloying at different temperatures, corresponding ligaments size increase with increasing temperature ( $c f$. Table 2 ), similar to what was observed in previous studies $[2,19]$. We observe here that the ligaments are very small (even in regions with the larger ligaments) compared to what could be expected from previous studies of laboratory produced percursors like FeCrNi, FeNi and TiNi [2,19]. for example ligaments were observed to be $4.8 \mu \mathrm{m}$ for porous $\mathrm{FeCr}$ (dealloyed $1 \mathrm{~h}$ at $1093 \mathrm{~K}$ ) [13] whereas we measured here $0.7 \mu \mathrm{m}$. It is known that surface diffusion rate of atom correlated to the melting (or sublimation) point of the element $[20,21]$. At the dealloying front, surface diffusion of Mo (melting point $T_{m} \sim 2903 \mathrm{~K}$ ) atoms could then be slower than those of Fe $\left(T_{m} \sim 1809 \mathrm{~K}\right)$ and $\mathrm{Cr}\left(T_{m} \sim 2163 \mathrm{~K}\right)$. Therefore, slower Mo atom diffusion can delay the dealloying process. In addition, the kinetics of ligament growth itself is considered to be ruled by surface relaxation caused by surface-diffusing atoms. Therefore, Mo atoms at the surface of the ligaments can act as "inhibitor" for the ligament growth directly, similar behavior was already observed when adding high melting temperature element in gold precursor $[22,23]$. It explains also in case of dealloying at $1033 \mathrm{~K}$ that Ti-rich inclusion (Mo-poor) presents larger ligaments than the Mo-rich matrix.

For electrochemical applications, smallest ligaments are desired however a composition evolution through the thickness is not good for corrosion resistance. Therefore the best candidate for corrosion resistance is the sample dealloyed for $1 \mathrm{~h}$ at $1033 \mathrm{~K}$. Its specific surface was then calculated and its corrosion resistance was measured in the following.
From the smallest ligaments size (LMD for $1 \mathrm{~h}$ ) at $1033 \mathrm{~K}$ specific surface $(S)$ can be calculated with the law formulated by Detsi et al. $[13,24]$

$$
S=\frac{3.7}{\rho d}
$$

with $\rho$ the density and $d$ the ligament size [24]. Assuming that for this material the value of the bulk density is equal to $7800 \mathrm{~kg} / \mathrm{m}^{3}$ (density of steel), we calculate a specific surface around $4 \times 10^{3} \mathrm{~m}^{2} / \mathrm{kg}$ (around $24 \times 10^{6} \mathrm{~m}^{2} / \mathrm{m}^{3}$ ). This value is quite consistent with low density nanoporous gold $\left(3 \times 10^{3} \mathrm{~m}^{2} / \mathrm{kg}\right.$ for $65 \mathrm{~nm}$ ligament thickness or around $17 \times 10^{6} \mathrm{~m}^{2} / \mathrm{m}^{3}$ ) [24]. This material presents a $\sigma$ phase which is not ideal from a mechanical point of view (the sigma phase is known to be very hard but brittle). However the high amount of $\mathrm{Cr}$ can have a good impact on corrosion resistance. Fig. 4 shows the polarization curve of the Incoloy 825 dealloyed at $1033 \mathrm{~K}$ for $1 \mathrm{~h}$. After the corrosion potential $(-0.6 \mathrm{~V})$, a passive region is observed to be maintained. Therefore, it can be concluded that the produced porous Incoloy 825 presents a good corrosion resistance.

A nickel based super alloy Incoloy 825 was chosen because of its high nickel concentration above the required parting limit as precursor for producing fully porous $\mathrm{FeCr}$ stainless steel by liquid metal dealloying in a Mg bath. Three different temperatures 1033, 1093 and $1153 \mathrm{~K}$ led to three different porous structures due to the influence of minor alloy elements. At $1033 \mathrm{~K}$, Ti induced polygonal shape Ti-rich inclusions $(\sim 10 \mu \mathrm{m})$, resulted in polygonal porous regions with larger ligaments $\sim 0.9 \mu \mathrm{m}$ than the matrix $\sim 0.14 \mu \mathrm{m}$. At $1093 \mathrm{~K}$, porous structure became more homogeneous, however the ligament size was $\sim 0.7 \mu \mathrm{m}$ which is much smaller than expected. This was explained to be possibly due to the presence of Mo in the ligaments, the low surface diffusion coefficient of which can reduce the growth kinetics of the ligaments. At the highest temperature $1153 \mathrm{~K}$, bi-modal porous structure was formed by a first dealloying reaction leading to large ligaments $(\sim 2.3 \mu \mathrm{m})$ containing $\mathrm{Ti}$,

Table 2

Measurement of the average ligament size from SEM images.

\begin{tabular}{|c|c|c|c|c|c|}
\hline & $\begin{array}{l}1033 \mathrm{~K} \\
\text { (Large ligaments) }\end{array}$ & $\begin{array}{l}1033 \mathrm{~K} \\
\text { (Small ligaments) }\end{array}$ & $1093 \mathrm{~K}$ & $\begin{array}{l}1153 \mathrm{~K} \\
\text { (Large ligaments) }\end{array}$ & $\begin{array}{l}1153 \mathrm{~K} \\
\text { (Small ligaments) }\end{array}$ \\
\hline Average ligament size $(\mu \mathrm{m})$ & $0.7 \pm 0.2$ & $0.14 \pm 0.03$ & $0.6 \pm 0.1$ & $2.0 \pm 0.5$ & $0.50 \pm 0.07$ \\
\hline
\end{tabular}



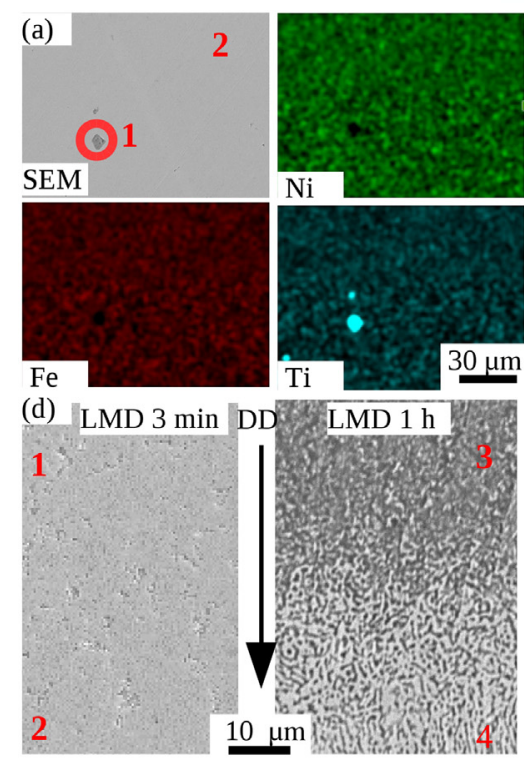

$30 \mu \mathrm{m}$
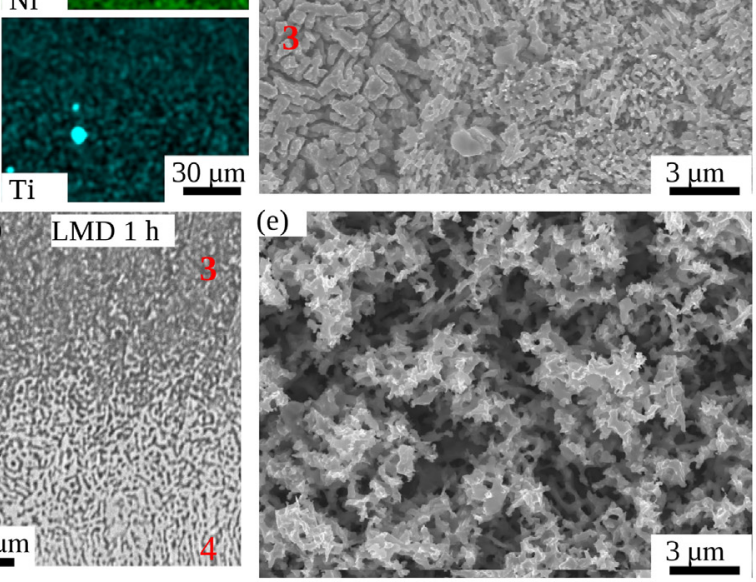

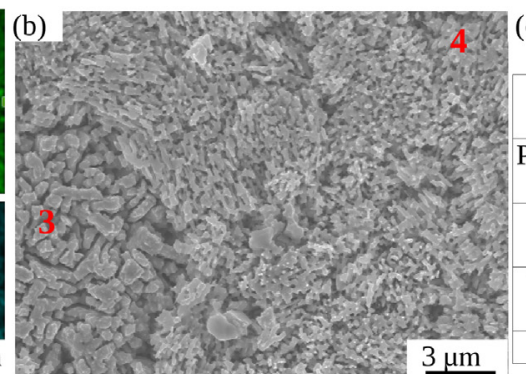

(c)

\begin{tabular}{|c|c|}
\hline at\% & ( $\mathrm{Fi}$ \\
\hline Precursor inclusion (1) & 0.65 \\
\hline Precursor matrix (2) & 0.02 \\
\hline Porous inclusion (3) & 0.71 \\
\hline Porous matrix (4) & 0.04 \\
\hline
\end{tabular}

(f)

\begin{tabular}{|c|c|}
\hline at $\%$ & $\frac{\mathrm{Mo}}{(\mathrm{Fe}+\mathrm{Cr}+\mathrm{Ti}+\mathrm{Mo})}$ \\
\hline 3 min surface (1) & 0.04 \\
\hline 3 min bulk (2) & 0.04 \\
\hline 1 h surface (3) & 0.24 \\
\hline 1 h bulk (4) & 0.04 \\
\hline
\end{tabular}

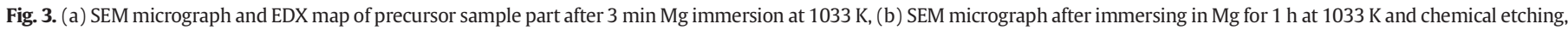

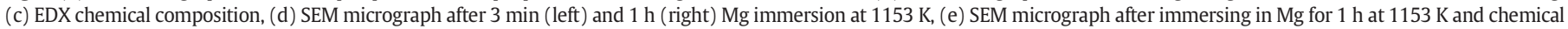

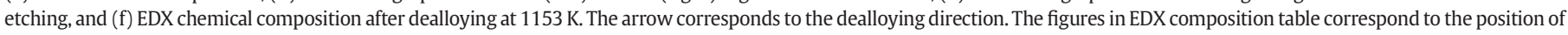
EDX analysis shown by red figures in SEM micrograph.

$\mathrm{Si}$, Mo, Fe and $\mathrm{Cr}$ followed by a second dealloying reaction creating small $(\sim 0.59 \mu \mathrm{m}) \mathrm{Si}$, Ti and Mo rich ligaments by dissolving Fe and Cr. Results show that a small amount of Mo in the precursor is a solution to modify surface diffusion and slow down coarsening. The presence of Mo in the commercial precursor highly decreases ligaments size and drastically increases specific surface $\left(4 \times 10^{3} \mathrm{~m}^{2} / \mathrm{kg}\right)$. The presence of inclusions in the precursor shows that multiple dealloying reactions are possible at the same time, with possible complex microstructure: local variation of the composition, bi-phased microstructure. We measure a corrosion resistance that makes the produced porous $\mathrm{FeCr}$-based alloy suitable for electro-chemistry applications. Especially the production of a hierarchical structure in a single step dealloying brings together high specific surface with small ligaments and a microfluidic flow control with large ligaments. In summary, we show that nano-architectured materials can be easily produced by dealloying raw commercial alloy. This opens many perspectives of new, low cost and possibly very complex and/or architectured microstructures.

\section{Acknowledgement}

This work was supported by ICC-IMR, Tohoku University, Japan; CMIRA 138249, Région Rhone-Alpes, France; Erasmus+ program, European union and theFrench ministry of research, France.

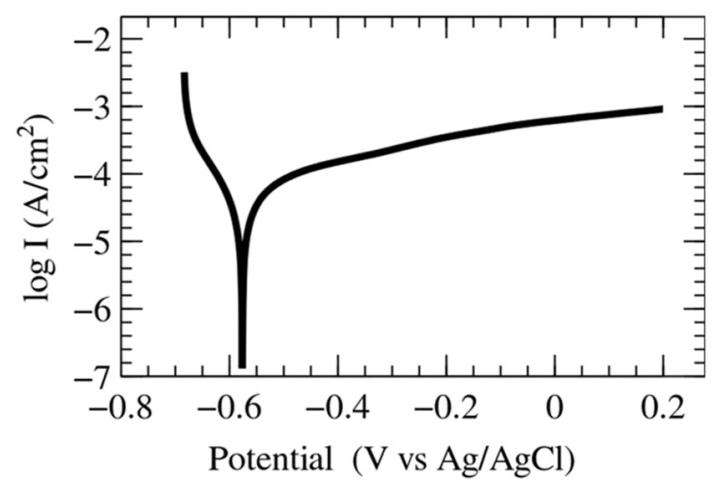

Fig. 4. Polarization curves of Incoloy 825 dealloyed in $\mathrm{Mg}$ melt at $1033 \mathrm{~K}$ for $1 \mathrm{~h}$.

\section{References}

[1] K. Sivula, R. Zboril, F.L. Formal, R. Robert, A. Weidenkaff, J. Tucek, J. Frydrych, M Gratzel, J. Am. Chem. Soc. 132 (21) (2010) 7436.

[2] T. Wada, H. Kato, Scr. Mater. 68 (2013) 723.

[3] H. Kato, T. Wada, M. Sadeghilaridjani, in: K. Sasaki, O. Suzuki, N. Takahashi (Eds.), Interface Oral Health Science, Springer 2016, p. 35.

[4] Y. Fukuzumi, T. Wada, H. Kato, in: K. Sasaki, O. Suzuki, N. Takahashi (Eds.), Interface Oral Health Science, Springer 2016, p. 93.

[5] D. Wei, Y. Koizumi, A. Chiba, Mater. Lett. 219 (2018) 256.

[6] D.M. Artymowicz, J. Erlebacher, R.C. Newman, Philos. Mag. 89 (2009) 1663.

[7] J. Li, W. Liu, Y. Ren, M. Shen, K. Yang, Acta Metall. Sin. 53 (5) (2017) 524.

[8] https://www.azom.com/article.aspx?ArticleID $=4245$.

[9] A. Takeuchi, A. Inoue, Mater. Trans. 46 (2005) 2817.

[10] T. Wada, K. Yubuta, A. Inoue, H. Kato, Mater. Lett. 65 (2011) 1076.

11] J.W. Kim, M. Tsuda, T. Wada, K. Yubuta, S.G. Kim, H. Kato, Acta Mater. 84 (2015) 497.

[12] J. Schindelin, I. Arganda-Carreras, E. Frise, V. Kaynig, M. Longair, T. Pietzsch, S. Preibisch, C. Rueden, S. Saalfeld, B. Schmid, J.Y. Tinevez, D.J. White, V. Hartenstein, K. Eliceiri, P. Tomancak, A. Cardona, Nat. Methods 9 (7) (2012) 676.

[13] M. Mokhtari, C. Le Bourlot, J. Adrien, A. Bonnin, T. Wada, J. Duchet-Rumeau, H. Kato, E. Maire, Mater. Charact. 144 (2018) 166.

[14] M. Sireesha, V. Shankar, S.K. Albert, S. Sundaresan, Mater. Sci. Eng. A 292 (1) (2000) 74.

[15] J. Kangazian, M. Shamanian, J. Manuf. Process. 26 (2017) 407.

[16] A. Jacob, E. Povoden-Karadeniz, E. Kozeschnik, Calphad 60 (2018) 16

[17] C.-C. Hsieh, W. Wu, Metallurgy 732471 (2012) 1.

[18] M. Stanislaw, J.C. Dubiel, Crit. Rev. Solid State Mater. Sci. 36 (2011) 191.

[19] M. Tsuda, T. Wada, H. Kato, J. Appl. Phys. 114 (2013) 113503.

[20] Q. Chen, K. Sieradzki, Nat. Mater. 12 (2013) 1102.

[21] I. McCue, A. Karma, J. Erlebacher, MRS Bull. 43 (1) (2018) 27.

[22] J. Snyder, P. Asanithi, A.B. Dalton, J. Erlebacher, Adv. Mater. 20 (24) (2008) 4883.

[23] X.-L. Ye, N. Lu, X.-J. Li, K. Du, J. Tan, H.-J. Jin, J. Electrochem. Soc. 161 (12) (2014) C517.

[24] E. Detsi, E. De Jong, A. Zinchenko, Z. Vukovic, I. Vukovic, S. Punzhin, K. Loos, G. ten Brinke, H.A. De Raedt, P.R. Onck, J.T.M. De Hosson, Acta Mater. 59 (2011) 7488. 